\title{
Effect of raised serum uric acid level on perinatal and maternal outcome in cases of pregnancy-induced hypertension
}

\author{
Qumrun Nassa Ahmed and Farhana Dewan
}

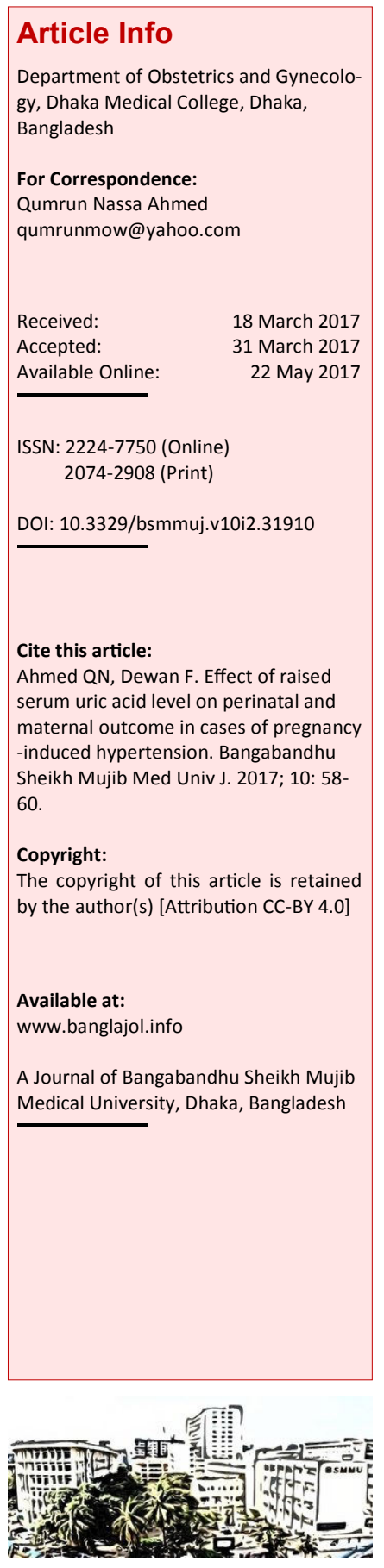

\begin{abstract}
The aim of this study was to find out the effects of raised serum uric acid level on perinatal and maternal outcome in cases of pregnancy-induced hypertension. One hundred pregnant women with gestational period beyond 28 weeks with pregnancy-induced hypertension-preeclampsia and eclampsia were included in this study and divided into two groups. Group A ( $n=65)$ patients with a serum uric acid level $>6 \mathrm{mg} / \mathrm{dL}$ was compared to Group B $(\mathrm{n}=35)$ patients with a uric acid level $<6 \mathrm{gm} / \mathrm{dL}$. It revealed that high uric acid level in patients with pregnancy-induced hypertension was a risk factor for several maternal complications like postpartum hemorrhage (Group A, 12 cases; Group B, 7 cases), postpartum eclampsia (Group A, 7 cases; Group B, 3 cases), abruptio placentae (Group A, 6 cases; Group B, 2 cases), HELLP syndrome (Group A, 2 cases; Group B, no case) and pulmonary edema (Group A, 3 cases; Group B, no case). In case of perinatal outcome, the birth weight, intrauterine growth retardation, intrauterine death, stillbirth and neonatal death rate were worse in Group A $1.9 \mathrm{~kg}, 46,19,7$ and 8 cases in comparison to Group B, where those were $2.1,13,6,2$, and 2 cases respectively. In conclusion, high uric acid in blood in patient with hypertensive disorders in pregnancy is a risk factor for several maternal complications.
\end{abstract}

\section{Introduction}

To give birth to a healthy baby is the most awaited event in a women's life, but elevated blood pressure during pregnancy impose great risk on the event. Hypertension affects between 7 and $15 \%$ of all pregnancies and is associated with as much as $22 \%$ of all perinatal deaths and $30 \%$ off all maternal death in USA.1 The incidence of hypertensive disorders and it's complications in developed Worlds have been reduced due to better antenatal care associated with improved socio-economic condition. Unfortunately its incidence is still high at developing countries and poses a greater challenge for health service providers working in the field of obstetrics, particularly in rural areas. In Bangladesh, preeclampsia and eclampsia contributes to $15 \%$ of maternal mortality rate. 2 Many clinical and biochemical parameters have been used to detect pregnancy -induced hypertension and to assess its severity. Unfortunately most of the available parameters till date are neither specific nor always sensitive. Hyperuremia is a characteristic biochemical feature of preeclampsia, but causes of both hyperuremia of preeclampsia has not yet been determined. It was studied that there is a high correlation between the severities of preeclampsia and concentration of serum uric acid. $\underline{3}$ On an average, plasma urate begins to rise six weeks before preeclampsia presumably due to decreased renal urate excretion. As there is limited availability and affordability of our patients and hospital, it is not possible to do various investigations to assess the fetal and maternal wellbeing. The triad of high blood pressure, edema and albuminuria is neither specific nor sensitive enough. So, a reliable blood examination is needed to solve our problem. The effect of raised serum uric acid level on perinatal and maternal outcome in cases of pregnancyinduced hypertension and preeclampsia was the aim of this study.

\section{Materials and Methods}

The study was performed on 100 women with pregnancy-induced hypertension from March to December 2009. Random sampling method is used to select the participants who were pregnant patients with gestational period beyond 28 weeks with pregnancy-induced hypertension and preeclampsia. The participants were categorized into two groups. Group A; those with a serum uric acid level of $>6 \mathrm{mg} / \mathrm{dL}(\mathrm{n}=65)$ and Group B; those with a serum uric acid level of $<6 \mathrm{mg} / \mathrm{dL} \quad(\mathrm{n}=35)$. 
Complications for mother as well as outcome of babies were documented. All data were collected in a preformed questionnaire from patients, who were admitted into the hospital. After admission diagnosis was made mostly on basis of history, clinical evaluation and available laboratory investigations. Serum uric acid were measured in all patients on admission.

\section{Results}

The mean (SD) uric acid level in Group A was 7.8 \pm $1.7 \mathrm{mg} / \mathrm{dL}$ whereas in Group B, it was $5.0 \pm 0.9 \mathrm{mg} /$ dL. The number of postpartum hemorrhage, postpartum eclampsia and abruptio placenta were more among the pregnancy-induced hypertensive patients with serum uric acid level $>6 \mathrm{mg} / \mathrm{dL}$ in comparison to $<6 \mathrm{mg} / \mathrm{dL}$ (Table I). HELLP syndrome and pulmonary edema were detected only in Group A. Considering the perinatal outcome, the number of cases of intrauterine growth retardation was 46, intrauterine death was 19, stillbirth was 7 and neonatal death was 8 .

It is obvious that maternal outcome in respect to postpartum hemorrhage, postpartum eclampsia, abruptio placenta, HELLP (Hemolysis, Elevated Liver enzymes, and Low Platelet count) syndrome and pulmonary edema Group A patients have more maternal morbidity than Group B patients. Neonatal complications are also more in Group A patients.

The caesarian section as the method of delivery was $50 \%$ cases in the both groups.

\section{Table I}

\section{Maternal and perinatal outcome with serum uric acid level}

\begin{tabular}{|c|c|c|c|}
\hline & \multicolumn{3}{|c|}{ Serum uric acid level } \\
\hline & $\begin{array}{l}>6 \mathrm{mg} / \mathrm{dL} \\
(\text { Group A) }\end{array}$ & $\begin{array}{l}<6 \mathrm{mg} / \mathrm{dL} \\
\text { (Group B) }\end{array}$ & $\mathrm{p}$ value \\
\hline \multicolumn{4}{|l|}{ Maternal outcome } \\
\hline Postpartum hemorrhage & 12 & 7 & \\
\hline Postpartum eclampsia & 7 & 3 & \\
\hline Abruptio placenta & 6 & 2 & \\
\hline HELLP syndrome & 2 & 0 & \\
\hline Pulmonary edema & 3 & 0 & \\
\hline \multicolumn{4}{|l|}{ Perinatal outcome } \\
\hline Mean (SD) birth weight in kg & $\begin{array}{r}1.9 \\
(0.5)\end{array}$ & $\begin{array}{r}2.1 \\
(0.5)\end{array}$ & 0.039 \\
\hline Intrauterine growth retardation & 46 & 13 & 0.001 \\
\hline Intrauterine death & 19 & 6 & 0.020 \\
\hline Stillbirth & 7 & 2 & 0.023 \\
\hline Neonatal death & 8 & 2 & 0.410 \\
\hline
\end{tabular}

\section{Discussion}

Most women with pregnancy-induced hypertensive disorders are symptom less, so, some laboratory tests are used for prediction, diagnosis and monitoring of disease progression. The diagnosis of preeclampsia is based on clinical findings and laboratory tests. Treatment is restricted to symptomatic management and expedited delivery is the only way to resolve the disease. A rising serum uric acid is now recognized as an early feature of preeclampsia and its measurement greatly increases the accuracy of diagnosis. Slemon and Bogert $\underline{4}$ first observed an association between the serum uric acid and the presence of pregnancy-induced hypertension.

Redman et al $\underline{5}$ stated that high serum uric acid levels were associated with high perinatal mortality rate. In a carefully controlled and extensive investigation, Pollak and Neettles $\underline{6}$ measured uric acid concentration in healthy pregnant female patients with preeclampsia. They determined the mean serum uric acid level in the last trimester of pregnancy for the normal woman to be $3.6 \pm 0.7$ gm\%, whereas the mean level for patient with histologically proven preeclampsia was $6.4 \pm 1.7$ $\mathrm{mg} \%$. Thus a significant increase in mean serum uric acid concentration was present in patients with preeclampsia as compared to those with normal pregnant women. Thus these authors showed the usefulness of serum uric acid measurements as an early and sensitive indicator of the presence of the preeclamptic state.

The study was planned to find out the effect of raised serum uric acid level and outcome of pregnancy in cases of postpartum hemorrhage preeclampsia and eclampsia. It showed that the range of serum uric acid ( $>6 \mathrm{mg} / \mathrm{dL})$ in Group A patients were $6.1-14.1 \mathrm{mg} / \mathrm{dL}$ (mean \pm SD:7.8 \pm 1.7 ) and Group B patients were $2.6-6.0 \mathrm{mg} / \mathrm{dL}$ (mean \pm SD: $5.0 \pm 0.9)$ and the difference was highly significant $(p=0.000)$. This study also showed that serum uric acid levels in preeclampsia and eclampsia group ranged 3.8-9.8 (mean \pm SD: $6.5 \pm$ 1.3) and $2.6-14.1 \mathrm{mg} / \mathrm{dL}$ (mean $\pm \mathrm{SD}: 7.2 \pm 2.3$ ) respectively and the difference was significant $(p=0.01)$. In this study, the range of age in patients were found within $16-35$ years. The highest incidence $(40 \%)$ found belonged to the age group of 21-25 years (data not shown). But in a study earned out by Masuda 7 the age range was (21-25). In this study, $82 \%$ of the patients were from lower class, $18 \%$ of the patient from middle class. In present study, in Group A and B, the percentage of urinary albumin test more than ++ were 75.4 and 64.5 , and less than ++ were 24.6 and 35.5. In this study, postpartum hemorrhage occurs in 12 cases, postpartum eclampsia is 7 cases, abrupsio placenta in 6 cases, HELLP 
syndrome in 2 cases and pulmonary edema in 3 cases, 1 maternal death due to cardio-respiratory failure due to hypoxic ischemic encephalopathy with septicemia. In Group B, postpartum hemorrhage occurs in 7 cases, postpartum eclampsia in 3 cases, abruptio placenta in 2 cases and no HELLP or pulmonary edema or no maternal mortality.

A study by Redman et al 18 showed that women in the severe pregnancy-induced hypertension group, the serum uric acid level was more than $6 \mathrm{mg} / \mathrm{dL}$ with low birth weight babies and associated with high perinatal mortality rate which correlate with this study. In the present study, the incidence of IUGR and stillbirth were not significantly high in patients with high serum uric acid which correlates with the finding of Suonio et al9 study.

High serum C-reactive protein concentration is also an indicator of pregnancy outcome in pre-eclamptic patient. 10

\section{Conclusion}

Measuring of uric acid level is simple and can easily be performed in any laboratory, so it can be a useful tool for screening of a pregnancy complicated by hypertension and an easy and inexpensive method for the detection of perinatal prognosis.

\section{References}

1. Arias F. Hypertensive disorder in pregnancy. In: Practical guide line to high-risk pregnancy and delivery. 3rd ed. Elsevier, 2008, pp 397-439.

2. Fauveau V, Kanji KA, Chakrabarty J, Houdhury AL. Causes of maternal mortality in rural Bangladesh. Bull WHO. 1988; 66: 643-51.

3. Standard HJ, Cadden JF. Blood chemistry in preeclampsia. Am J Obstet Gynaecol. 1934; 28: 856.

4. Slemons JM, Bogert LJ. The serum uric acid content maternal and foetal blood. J Biol Chem. 1917; 32: 63 -65 .

5. Redman CWG, Wilium GF, Jones DD, Wilkinson RH. Plasma urate and serum deoxycytidylate deaminase measurement for the early diagnosis of preeclampsia. Br J Obstet Gynaecol. 1977; 84: $904-$ 08.

6. Pollak VE, Nettles JB. The kidney in toxemia of pregnancy: A clinical and pathological study based on renal biopsies. Medicine 1960; 39: 469.

7. Begum M. Hypertensive disorders of pregnancy in SSMCH (Dissertation). Dhaka, Bangladesh College of Physician and Surgeons, 1994, p 69.

8. Redman CW, Beilin LJ, Bonnar J, Wilkinson RH. Plasma urate measurements in predicting fetal death in hypertensive pregnancy. Lancet 1976; 26: 1370-73.

9. Suoio S. Nummi S, Jouppila P, Reinila M. Serum uric acid in the late pregnancy in normal and toxaemic patients. Ann Chio Gynecol Fenn. 1972; 61: $202-05$

10. Sultana S, Akhter P, Dabee S, Akter S, Khatun M. Serum C-reactive protein concentration in preeclamptic women: Effect on pregnancy outcome. Bangabandhu Sheikh Mujib Med Univ J. 2016; 8: 30-36. 